\title{
CARACTERIZAÇÃO DAS CONDIÇÕES CLIMÁTICAS DE CÁCERES/MT- BRASIL, NO PERÍODO DE 1971 A 2009: SUBSÍDIO ÀS ATIVIDADES AGROPECUÁRIAS E TURÍSTICAS MUNICIPAIS
}

\author{
CHARACTERIZATION OF CLIMATIC CONDITIONS FROM CÁCERES/MT, \\ BRAZIL, FROM 1971 TO 2009: SUBSIDY FOR AGRICULTURAL ACTIVITIES \\ AND TOURIST CITY
}
CARACTERIZACIÓN DE LAS CONDICIONES CLIMÁTICAS DE CÁCERES/MT, BRASIL, DESDE 1971 HASTA 2009: SUBVENCIONES PARA ACTIVIDADES AGRÍCOLAS Y TURÍSTICAS DE LA CIUDAD
Sandra Mara Alves da Silva Neves - Universidade do Estado de Mato Grosso - Cáceres - Mato Grosso - Brasil ssneves@unemat.br
Maria Cândida Moitinho Nunes - Universidade do Estado de Mato Grosso - Cáceres - Mato Grosso - Brasil nunes.candida@gmail.com
Ronaldo José Neves - Universidade do Estado de Mato Grosso - Cáceres - Mato Grosso - Brasil rjneves@terra.com.br

\section{Resumo}

\begin{abstract}
A economia de Mato Grosso é sustentada na produção agropecuária, que é extremamente dependente das condições climáticas e, nos últimos anos, o estado tem investido no turismo. Situação semelhante vem ocorrendo em Cáceres-MT onde, devido às temperaturas elevadas e longo período de estiagem, necessita-se de informações dos componentes climáticos para o adequado planejamento e desenvolvimento, local e regional. Para execução da pesquisa foram utilizados dados meteorológicos da Estação do INMET de Cáceres, referentes ao período de 1971-2009, para caracterização de aspectos climáticos e cálculo do balanço hídrico climatológico. A estimativa da evapotranspiração potencial foi realizada conforme Thornthwaite (1948) e 0 cálculo do balanço hídrico conforme Thornthwaite \& Mather (1985), considerando uma capacidade de água disponível (CAD) de 100 $\mathrm{mm}$. A temperatura média anual foi de $26,24^{\circ} \mathrm{C}$. A temperatura média mensal mais alta ocorre no mês de outubro $\left(28,01^{\circ} \mathrm{C}\right)$ e as médias mensais mais baixas nos meses de junho e julho, 23,39 e $23,36^{\circ} \mathrm{C}$, respectivamente. A precipitação total anual é de $1.335 \mathrm{~mm}$. 0 período de maior concentração pluvial média ocorre de dezembro a março e o período de maior estiagem ocorre de junho a agosto. A evapotranspiração potencial média é de $1.650,55 \mathrm{~mm}$.
\end{abstract}

Palavras-chave: sazonalidade, disponibilidade hídrica, clima, balanço hídrico.

\section{Abstract}

The economy of Mato Grosso state is based on agriculture production, that is extremely dependent on climatic condition and in the last years the state has invested the tourism. Similar situation has occurred in Cáceres, where, due to high temperatures and long periods of drought, information needs of climate components for proper planning and development, local and regional level. The research was done using the data of INMET weather station in Cáceres, in the period from 1971-2009, for characterization of general climate aspects; and the climatic water balance. The potential evapotranspiration estimative was realized according to Thornthwaite (1948) and the water balance calculus according to Thornthwaite \& Mather (1985), considering the capacity of available water (CAD) of $100 \mathrm{~mm}$. The annual average temperature was $26.24^{\circ} \mathrm{C}$. The more high monthly 
temperature occurs in the October $\left(28.01^{\circ} \mathrm{C}\right)$, and the monthly average temperature occurs in June and July, 23.39 e $23.36^{\circ} \mathrm{C}$, respectively. The annual precipitation is of $1.335 \mathrm{~mm}$. The period of greater average pluvial concentration occurs from December to March, and the period of more drought occurs from June and august. The average total potential evapotranspiration is $1650.55 \mathrm{~mm}$.

Key words: seasonality, hydric availability, climate, water balance.

Resumen

Economía de Mato Grosso se sustenta en la producción agrícola, que es extremadamente dependiente de las condiciones climáticas y en los últimos años el Estado ha invertido en el turismo. Una situación similar ha ocurrido en Cáceres-MT, en donde, debido a las altas temperaturas y largos períodos de sequía, las necesidades de información de los componentes del clima para la adecuada planificación y desarrollo, a nivel local y regional. Para realizar la investigación se utilizaron la estación meteorológica de INMET Cáceres, para el período 1971-2009, para caracterizar los aspectos del clima y el cálculo del balance hídrico climático. La estimación de la evapotranspiración potencial se realizó de acuerdo a Thornthwaite (1948) y el cálculo del balance hídrico según Thornthwaite (1985), considerando una capacidad de retención de agua (CAD) de $100 \mathrm{~mm}$. La temperatura media anual fue de $26,24^{\circ} \mathrm{C}$. La más alta temperatura media mensual se produce en octubre $\left(28.01^{\circ} \mathrm{C}\right)$ y el más bajo promedio mensual en junio y julio, 23.39 y $23.36^{\circ} \mathrm{C}$, respectivamente. La precipitación anual total es de $1.335 \mathrm{~mm}$. El período de mayor concentración de la precipitación media se produce a partir de diciembre a marzo y el período de mayor sequía se produce entre junio y agosto. La evapotranspiración potencial media es de 1650,55 mm.

Palabras clave: estacionalidad, disponibilidad de agua, clima, balance hídrico.

\section{Introdução}

O clima é a chave da configuração da vegetação, dos processos morfogenéticos, da distribuição da fauna, dos fluxos dos rios e dos suprimentos de água. Todos esses fatores são de vital importância para a formação de um quadro turisticamente atraente e funcional (MARTÍN, 1999). Ainda de acordo com o autor, a temperatura, insolação, precipitação, vento, umidade e o nevoeiro são os elementos climatológicos que mais influenciam a atividade turística.

Obalançohídricoclimatológicoéuminstrumentoagrometeorológico útil e prático para caracterizar o fator umidade do clima, sendo importante na caracterização climática regional quanto à disponibilidade hídrica (VIANELLO \& ALVES, 1991; SENTELHAS, 1998), além de informar sobre a distribuição das deficiências e excessos de chuva (SORIANO, 2000) e auxiliar na definição da aptidão agrícola da região em estudo (CAMARGO et al., 1974), podendo, dessa forma, ser utilizado para o planejamento, uso e manejo da terra.

$\mathrm{Na}$ estimativa da evapotranspiração potencial para o balanço hídrico, é importante o conhecimento do tipo da formação vegetal que recobre o solo. Em áreas que apresentam grande extensão territorial, como 
é o caso do município de Cáceres, têm sido amplamente empregadas as geotecnologias, como o Sistema de Informação Geográfica (SIG) e imagens de Sensoriamento Remoto, para elaboração de mapas de cobertura vegetal e uso da terra e em estudos de balanço hídrico. Considerado nesse contexto como uma ferramenta relativamente nova, é capaz de demonstrar as características, o comportamento e a variação espacial e temporal da disponibilidade hídrica de uma determinada região, auxiliando assim a tomada de decisão (D’ ANGIOLELLA; VASCONCELLOS; ROSA, 2005).

A investigação das características climáticas de Cáceres se faz necessária, devido ao pouco estudo da temática e pela necessidade de geração de informações que subsidiem ordenamento territorial das atividades antrópicas. Face ao exposto, este artigo tem como propósito caracterizar e analisar as condições climáticas do município de Cáceres, no período de 1971 a 2009, visando subsidiar com informações a gestão das atividades agropecuárias e turísticas.

\section{Material e métodos}

O município de Cáceres está localizado na região sudoeste de Mato Grosso, entre as latitudes $15^{\circ} 27^{\prime}$ e $17^{\circ} 37^{\prime}$ sul e as longitudes $57^{\circ} 00^{\prime}$ e $58^{\circ} 48$ ' oeste (Figura 1), com área de $24.398,399$ km² (IBGE, 2002), a uma altitude de $118 \mathrm{~m}$. Cáceres integra a mesorregião do Centro-Sul matogrossense e a microrregião do Alto Pantanal, distando $215 \mathrm{~km}$ da capital. O clima, segundo classificação de Köppen, é tropical quente e úmido, com inverno seco (Awa).

Os dados utilizados foram: precipitação, temperatura do ar (máxima, mínima e média), umidade relativa do ar e insolação, obtidos da Estação Meteorológica do Instituto Nacional de Meteorologia (INMET) de Cáceres (código - 01657000), localizada no Instituto Federal de Mato Grosso (IFMT). Estes se referem ao período de observação de 1971 a 2009 (39 anos) e foram disponibilizados em meio analógico e inseridos no Banco de Dados Geográficos - BDG no ArGis da Esri. Para realizar as análises foram introduzidas no BDG informações relativas à cobertura vegetal e uso da terra, derivadas do Probio Pantanal (2004), e de solos do Plano de Conservação da Bacia do Alto Paraguai (1997).

A estimativa da evapotranspiração potencial foi realizada conforme Thornthwaite (1948) e o cálculo do balanço hídrico conforme Thornthwaite 
e Mather (1985), considerando-se uma capacidade de água disponível (CAD) de $100 \mathrm{~mm}$. Foram utilizados dados do total pluvial médio mensal (P) e de temperatura média mensal do ar (T).

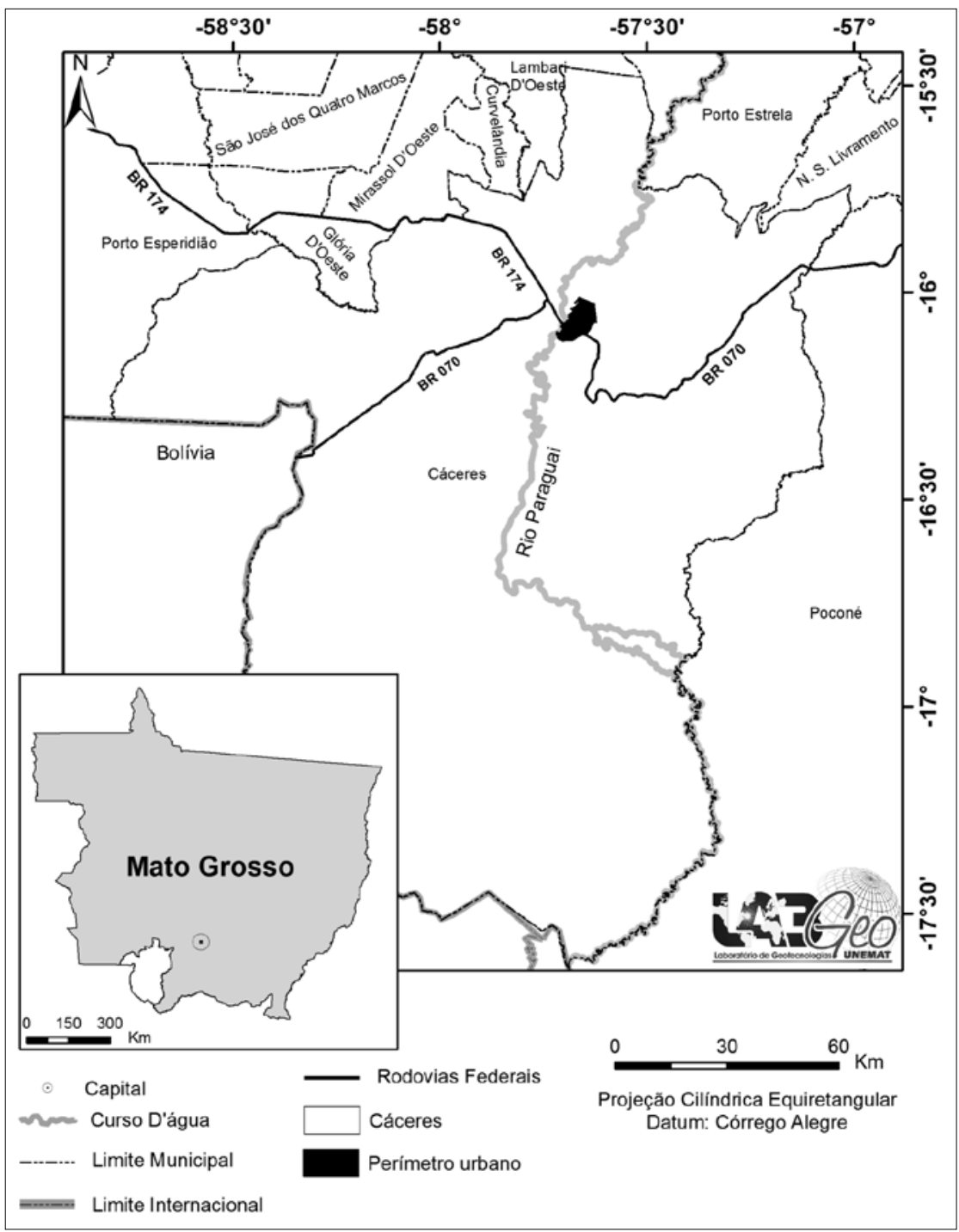

Figura 1 - Localização do município de Cáceres, MT. 
Artigo

Resultados e discussão

A crescente ocupação do sudoeste de Mato Grosso tem provocado o desmatamento de grande parte da vegetação natural para a exploração agropecuária, sem o adequado uso e manejo do solo, originando áreas de alta fragilidade ambiental e suscetibilidade à erosão hídrica. Nesse sentido, as informações a respeito das precipitações são de extrema importância para sustentabilidade e desenvolvimento da atividade agropecuária local e no planejamento da atividade turística.

A análise dos dados de precipitação do município de Cáceres mostra um total anual $1.335 \mathrm{~mm}$, em que o período de maior concentração pluvial média $(62,68 \%)$ ocorre de dezembro a março. Tal índice difere dos resultados estimados por Cadavid García (1984), quando da sua análise da precipitação de Cáceres (período de 10 anos - 1971 a 1981). Nesse estudo, estimou que $82,4 \%$ da chuva média anual de $1.262 \pm 46 \mathrm{~mm}$ (intervalo de confiança de $90 \%$ ) se concentram no período de outubro a março. Ainda em relação à precipitação, a frequência de ocorrência mostra que o mês mais chuvoso é janeiro e que o período de maior estiagem ocorre de junho a agosto, com apenas 4,9\% do total pluviométrico anual (Figura 2).

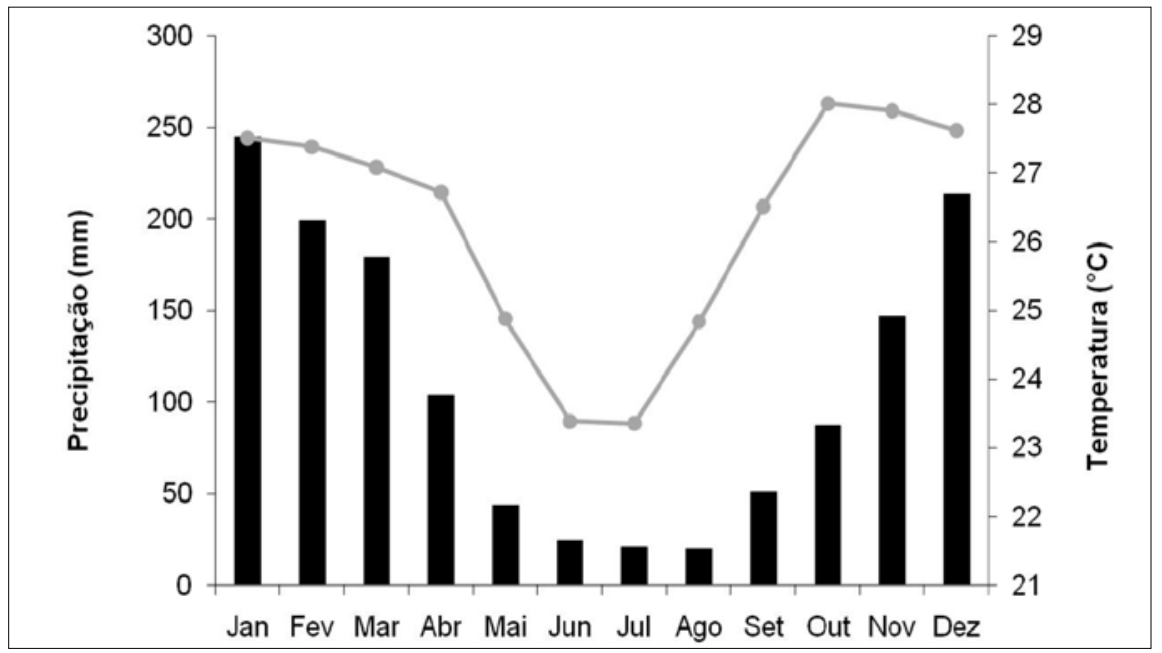

Figura 2 - Climograma de Cáceres/MT (1971-2009). 
A partir da análise do climograma, verifica-se que as maiores temperaturas médias ocorrem no período úmido e as menores no período seco, configurando o clima local em duas estações definidas pela distribuição espacial e temporal das chuvas. A análise do climograma evidencia uma variabilidade da precipitação pluvial dentro do período analisado, podendo-se observar que a chuva nesta região é maior nos meses associados à entrada de maior radiação solar no Hemisfério Sul, ou seja, à atuação de sistemas convectivos de mesoescala, no caso a Zona de Convergência do Atlântico Sul (ZCAS), que provoca chuvas convectivas em grande parte do Brasil, atingindo também esta área.

Nas atividades agrícolas, a temperatura pode ser decisiva para o conforto térmico dos animais e para a escolha do tipo de cultura a ser adotada. No turismo, este recurso natural não deve ser ignorado, pois é considerado como elemento importante, ao influenciar no conforto humano e na sensação de bem-estar. A temperatura média anual de Cáceres, para o período de observação, foi de $26,24^{\circ} \mathrm{C}$. A temperatura máxima absoluta foi de $41,2^{\circ} \mathrm{C}$ (outubro de 2008) e a mínima absoluta de $-1,0^{\circ} \mathrm{C}$ (junho de 1996). A temperatura média mensal mais alta ocorre no mês de outubro $\left(28,01^{\circ} \mathrm{C}\right)$ e as temperaturas médias mensais mais baixas ocorrem nos meses de junho e julho, 23,39 e 23,36 ${ }^{\circ} \mathrm{C}$, respectivamente (Figura 3). O ideal térmico para o organismo humano varia conforme a latitude de origem do grupo considerado. A maioria dos estudiosos admite que, para as populações das latitudes médias, os limites oscilam entre $18^{\circ} \mathrm{C}$ e $22^{\circ}$ C (CONTI, 1997). Na perspectiva apresentada, a temperatura média anual da região de Cáceres é superior à sugerida; apenas no mês de julho ocorre a temperatura média mensal dentro do limite proposto como ideal. Mas a situação apresentada, de acordo com Conti (1997), não constitui problema para os fluxos turísticos entre diferentes faixas de latitude, uma vez que a diferenciação das condições geográficas se torna fator muito relevante e, muitas vezes, um forte atrativo nesse campo. Por exemplo, o habitante de latitudes altas e médias sente-se motivado a conhecer regiões tropicais com suas elevadas temperaturas médias e exuberante manifestação de biodiversidade. Áreas de grande riqueza faunística como o Pantanal, que ocupa cerca de $270.000 \mathrm{~km}^{2}$ no Centro-Oeste brasileiro e no território boliviano, são relíquias geográficas das baixas latitudes. 


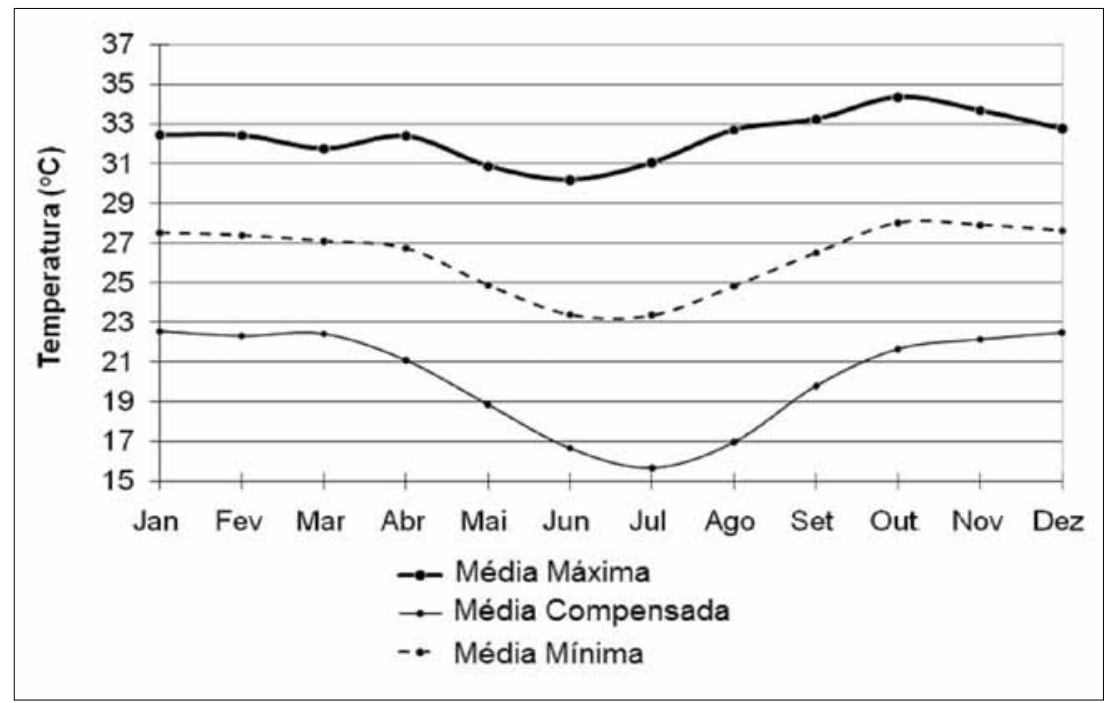

Figura 3 - Temperaturas mínima, média e máxima de Cáceres/MT (1971-2009).

Referenteà insolação, o total anual registrado foi de aproximadamente 1.874,65 horas de brilho solar. A distribuição mensal desse parâmetro variou de 106,02 horas, no mês de setembro, a 224,35 horas, no mês de julho (Figura 4).

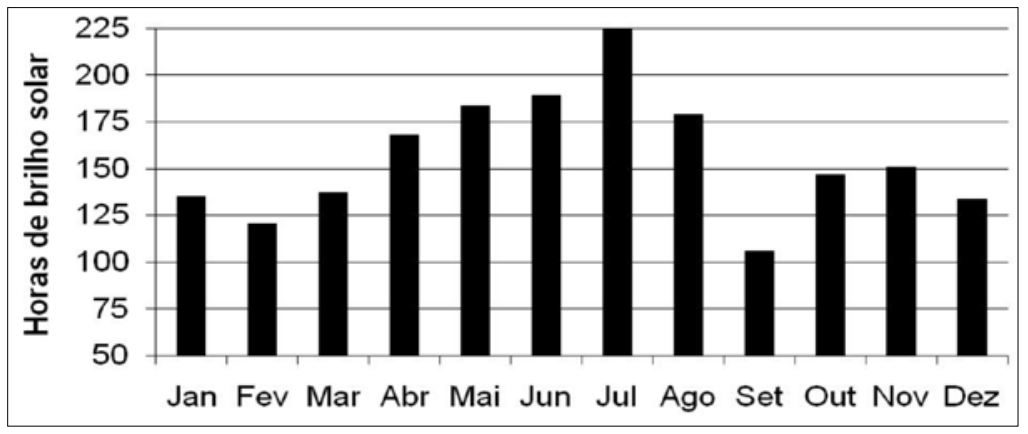

Figura 4 - Totais mensais de insolação em Cáceres/MT (1971-2009).

A temperatura do solo depende, em grande parte, da densidade de fluxo e da duração da radiação solar e das condições do solo, especialmente 
cobertura superficial e teor de água (DERPSCH et al., 1985). As condições de luminosidade elevada associada a temperaturas altas, dependendo do tipo de cultura, influenciam no ciclo de desenvolvimento do vegetal, podendo ocorrer redução do ciclo e antecipação da fase reprodutiva, causando queda da produção durante certas épocas do ano, como é o caso da alface, por exemplo, cultivada amplamente pelos pequenos agricultores em Cáceres.

No tocante à atividade do turismo, há estudos que evidenciam que a luminosidade influencia na sensação de bem-estar do turista, estando associada ao sentimento de satisfação. Nesse sentido, os dados assinalam as boas condições apresentadas pelo mês de julho para a realização do turismo, com a ausência de nebulosidade.

A investigação da umidade relativa do ar mostrou que a média anual apresentada na série foi de $78,50 \%$. A menor umidade relativa média do ar, 57\%, ocorreu em setembro de 2008 e a maior, 89\%, em 1979 e 1982 . A Figura 5 apresenta a relação entre a variação da umidade relativa do ar e a temperatura, já que o conforto humano depende tanto da temperatura do ar como de sua umidade relativa.

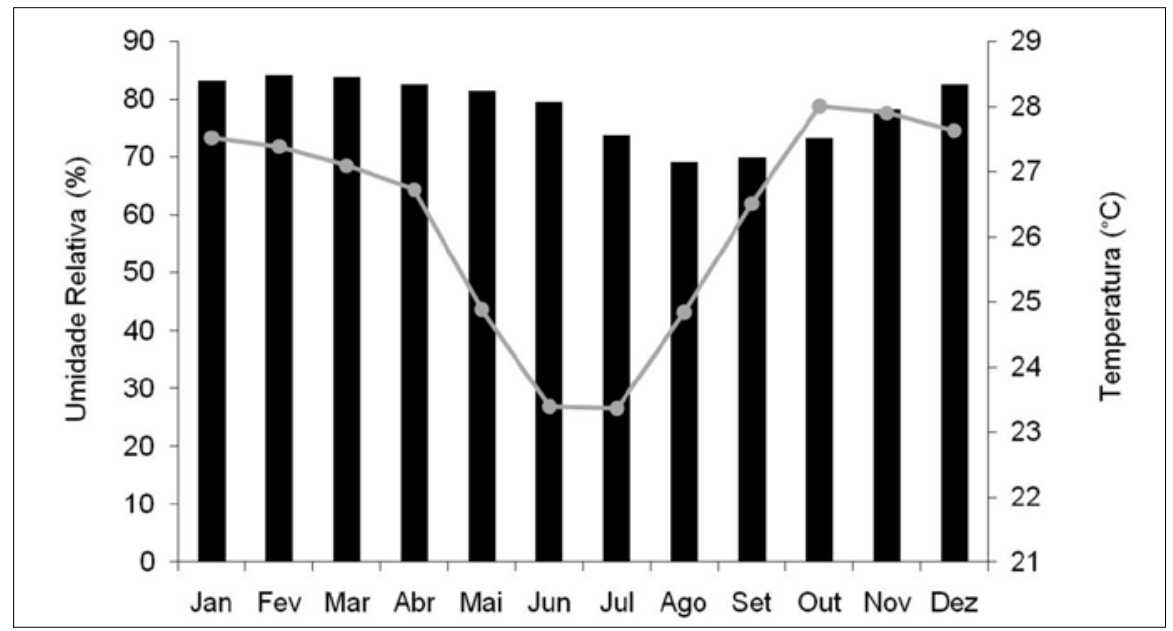

Figura 5 - Umidade relativa média do ar e temperatura média em Cáceres/MT (1971-2009).

Em Cáceres, nos meses do período seco, a umidade relativa média é superior a 69\% (agosto) e a temperatura média do período investigado, 
no mesmo mês foi de $24,8^{\circ} \mathrm{C}$. A combinação dos dois elementos climáticos provoca desconforto, que as pessoas consideram ser decorrente do calor, mas que na realidade é devido à umidade relativa do ar, que faz com que parte dos habitantes se sinta mal. Se o desconforto térmico interfere na vida da população local, consequentemente pode influenciar na atividade turística, pois o conforto térmico é o estado mental que expressa a satisfação do homem com o ambiente térmico que o circunda (LAMBERS, 1994).

Com base na metodologia de Thornthwaite (1948), obteve-se para Cáceres um fator "I", que representa o nível de calor da região igual a 148,13. A partir desse valor, foi calculado o fator "A", que expressa o índice térmico regional, obtendo-se um valor de 3,66. A evapotranspiração potencial total média é de 1.650,55 mm, sendo, portanto, 19,12\% maior que a precipitação total média. A evapotranspiração potencial é intensa na maior parte do ano, sendo inferior à precipitação apenas no período de dezembro a março (Tabela 1). Isso foi confirmado pelos resultados obtidos por Rossato et al. (2004), ao verificarem que nas regiões Centro-Oeste e Sudeste o percentual de armazenamento de água no solo é baixo entre os meses de julho e setembro, o que está associado ao período em que ocorre a diminuição da precipitação e aumento da ETP em quase todo país.

Tabela 1 - Balanço hídrico climático normal para Cáceres/MT (1971-2009).

\begin{tabular}{lccrrrrrrrr}
\hline Mês & $\begin{array}{l}\text { T } \\
{ }^{\circ} \mathbf{C}\end{array}$ & P & ETP & P-ETP & \multicolumn{1}{c}{ NAC } & ARM & ALT & ETR & DEF & EXC \\
\hline Janeiro & 27,51 & 244,94 & 173,64 & 71,30 & 0,00 & 100,00 & 0,00 & 173,64 & 0,00 & 71,30 \\
Fevereiro & 27,38 & 198,92 & 149,40 & 49,52 & 0,00 & 100,00 & 0,00 & 149,40 & 0,00 & 49,52 \\
Março & 27,09 & 179,29 & 153,08 & 26,21 & 0,00 & 100,00 & 0,00 & 153,08 & 0,00 & 26,21 \\
Abril & 26,72 & 103,64 & 136,35 & $-32,70$ & $-32,70$ & 72,18 & $-27,82$ & 131,47 & 4,88 & 0,00 \\
Maio & 24,88 & 44,05 & 105,18 & $-61,13$ & $-93,83$ & 39,24 & $-32,94$ & 76,99 & 28,19 & 0,00 \\
\hline Junho & 23,39 & 24,20 & 80,78 & $-56,59$ & $-150,42$ & 22,32 & $-16,92$ & 41,12 & 39,67 & 0,00 \\
Julho & 23,36 & 21,09 & 82,70 & $-61,61$ & $-212,03$ & 12,08 & $-10,24$ & 31,33 & 51,36 & 0,00 \\
Agosto & 24,84 & 20,14 & 106,48 & $-86,34$ & $-298,37$ & 5,11 & $-6,97$ & 27,11 & 79,37 & 0,00 \\
Setembro & 26,51 & 50,96 & 134,73 & $-83,77$ & $-382,14$ & 2,22 & $-2,89$ & 53,85 & 80,88 & 0,00 \\
\hline Outubro & 28,01 & 87,12 & 176,86 & $-89,74$ & $-471,88$ & 0,91 & $-1,31$ & 88,43 & 88,43 & 0,00 \\
Novembro & 27,91 & 147,04 & 174,77 & $-27,73$ & $-499,61$ & 0,69 & $-0,22$ & 147,26 & 27,51 & 0,00 \\
\hline Dezembro & 27,62 & 213,61 & 176,58 & 37,03 & 0,00 & 100,00 & 99,31 & 176,58 & 0,00 & 0,00 \\
\hline Ano & 26,27 & $1.335,00$ & $1.650,55$ & $-315,55$ & & & 0,00 & $1.250,26$ & 400,30 & 147,03 \\
\hline
\end{tabular}

$\mathrm{T}=$ temperatura média; $\mathrm{P}=$ precipitação total média; $\mathrm{ETP}=$ evapotranspiração potencial média; $\mathrm{NAC}=$ negativo acumulado; $\mathrm{ARM}=$ armazenamento; $\mathrm{ALT}=$ alteração do armazenamento; $\mathrm{ETR}=$ evapotranspiração real; DEF = déficit hídrico; EXC = excedente hídrico. 
A partir da Tabela 1, observa-se a presença de duas estações bem definidas, o período de seca, em que a precipitação é menor do que a evapotranspiração potencial média (ETP), e o período chuvoso, no qual a precipitação é maior do que a ETP. Dessa forma, em Cáceres o período chuvoso é de quatro meses (dezembro a março) e o período de seca é de oito meses (abril a novembro). Este comportamento também é observado em relação ao excedente e ao déficit hídrico, sendo esse último inexistente no município no período de dezembro a março. O déficit hídrico anual médio é 400,30 mm e o excedente hídrico é de 147,03 mm (Figura 6).

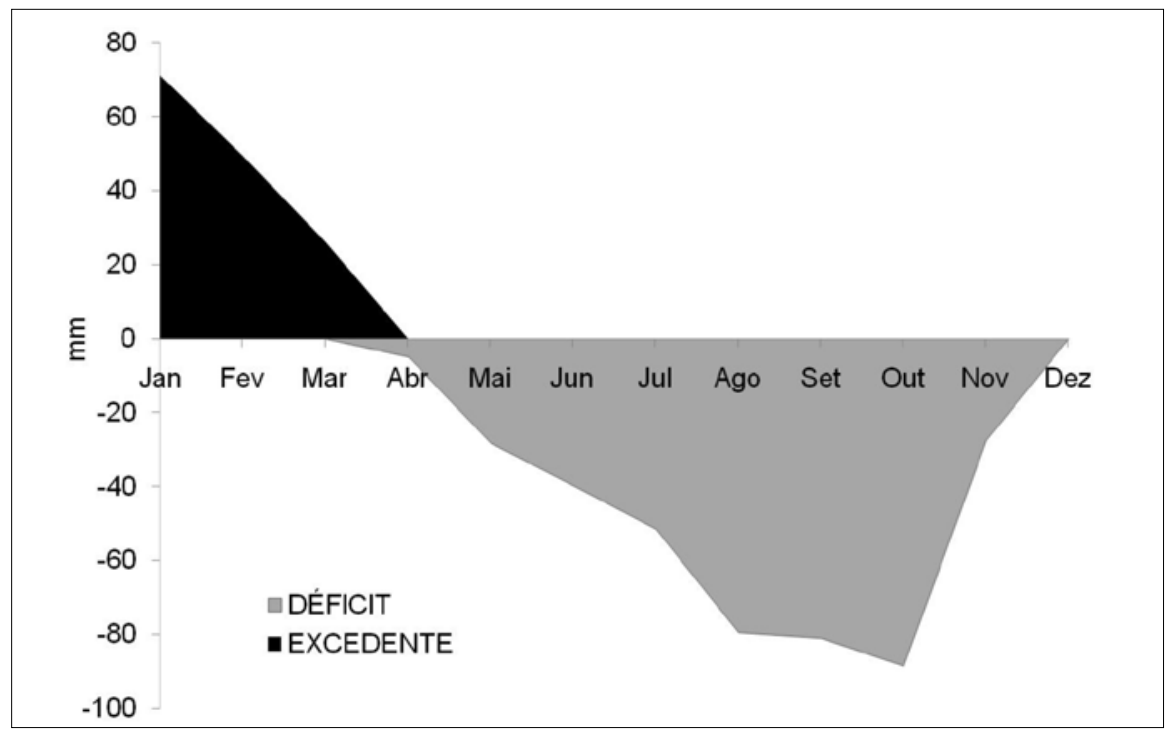

Figura 6 - Período de déficit hídrico e de excedente hídrico para o município de Cáceres/MT, segundo dados do INMET (1971-2009).

Retomando os estudos de Cadavid García (1984) em relação aos dados climáticos de Cáceres, referentes ao período de 1971 a 1981, a precipitação média anual apresentada foi de $1.262 \pm 46 \mathrm{~mm}$, sendo que $82,4 \%$ desse total ocorrem no período de outubro a março. No entanto, no Zoneamento Agroecológico do sudoeste do estado de Mato Grosso de 1994 (RESENDE et al., 1994), para o período de 1925 a 1982, foi verificada uma precipitação média anual para Cáceres de $1.277 \mathrm{~mm}$, com um déficit hídrico em torno de $300 \mathrm{~mm}$ e excedente hídrico de $200 \mathrm{~mm}$. 
Esses dados podem indicar que está ocorrendo um aumento no déficit hídrico anual e redução do excedente hídrico ao longo do tempo. De acordo com o exposto, deve existir uma readequação do uso dos recursos hídricos e do uso e manejo da terra. Neste sentido, as informações obtidas a partir desse balanço hídrico climático poderão ser utilizadas para indicar a época mais apropriada ao longo do ano para o preparo do solo, semeadura e plantio, bem como a necessidade de sistemas de irrigação e drenagem nas áreas agricultáveis de Cáceres.

No tocante ao turismo, a vegetação é um dos atrativos utilizados no desenvolvimento da atividade no Pantanal de Cáceres. Ao ocorrer o déficit hídrico, as espécies vegetais das formações de Savana (Cerrado) perdem suas folhas e exuberância, modificando completamente a paisagem, com exceção da Floresta Estacional Semidecidual, situada à margem dos rios pantaneiros, cuja perda é parcial.

Segundo Pereira et al. (2002), a densidade de estações meteorológicas recomendada pela Organização Mundial de Meteorologia (OMM) é de uma distância máxima de $150 \mathrm{~km}$. Com base nessa informação, os dados gerados pela estação meteorológica de Cáceres podem ser aplicados para todo o município. Porém, as caracterizações de alguns dos elementos climáticos de Cáceres não se aplicam à totalidade do município, tendo como exemplo o balanço hídrico, que apresenta déficit hídrico para todo o município, mas ocorre apenas nos ambientes da depressão do rio Paraguai, onde encontra-se a sede municipal, e na Província Serrana. O ambiente pantaneiro de Cáceres, na sua porção centro-sul, mesmo no período seco como no mês de julho, se apresenta alagado, ou seja, em estresse hídrico.

As pesquisas de Cadavid García (1984) nos Pantanais de Nhecolândia e Paiaguás demonstraram também que o balanço hídrico, estimado pelo método de Thornthwaite \& Mather (1948), considerando os fatores climáticos locais, constitui apenas um componente a ser acatado entre os fatores climáticos e hidrológicos da bacia, uma vez que os solos pantaneiros normalmente recebem mais água que o próprio aporte pluvial local.

A capacidade de água disponível (CAD) adotada no referido método é de $100 \mathrm{~mm}$, porém esta medida não se aplica à porção centro-sul do Pantanal de Cáceres, onde a dinâmica das águas de superfície é vinculada a fatores como declividade e à descarga dos principais rios que atravessam a área, aliada ao regime climático, natureza dos solos e suporte geológico (RADAMBRASIL, 1982). 


\section{Considerações finais}

A partir de uma série de 39 anos de dados meteorológicos, verificouse que o município de Cáceres apresenta uma precipitação total anual de $1.335 \mathrm{~mm}$, a qual se concentra no período de dezembro a março, sendo que o mês de janeiro é o de maior precipitação. O período de seca é de oito meses (abril a novembro), sendo mais intenso de junho a agosto, com apenas 4,9\% do total pluviométrico anual.

A temperatura média anual de Cáceres é de $26,24^{\circ} \mathrm{C}$. As maiores temperaturas ocorrem no período úmido e as menores no período seco, configurando o clima local em duas estações definidas pela distribuição espacial e temporal das chuvas. Esses dados são decorrentes, principalmente, do total anual de insolação, o qual é de 1.874,65 horas de brilho solar, variando de 106,02 horas (setembro) a 224,35 horas (julho).

A evapotranspiração potencial total média é de 1650,55 mm, sendo, 19,12\% maior que a precipitação total média. A evapotranspiração potencial é intensa na maior parte do ano, sendo inferior à precipitação apenas no período de dezembro a março.

A umidade relativa média do ar é de $78,50 \%$. No período seco, destaca-se o mês de agosto, em que a umidade relativa média fica em torno de $69 \%$ e a temperatura média é de $24,8^{\circ} \mathrm{C}$. A combinação desses dois elementos provoca um desconforto térmico, o qual interfere na vida da população e, consequentemente, na atividade turística local.

O déficit hídrico anual médio é 400,30 mm e o excedente hídrico é de apenas 147,03 mm. Apenas de dezembro a março, identificado como o período chuvoso, não existe déficit hídrico no município. Esses dados são extremamente preocupantes do ponto de vista agropecuário, indicando a necessidade de uso e manejo adequado dos recursos naturais. Salientase, entretanto, que esses resultados, obtidos a partir do balanço hídrico, devido à capacidade de água disponível adotada (100 mm), não se aplicam à porção centro-sul do Pantanal de Cáceres devido à dinâmica das águas de superfície que é vinculada a fatores como declividade e descarga dos principais rios que atravessam a área, aliado ao regime climático, natureza dos solos e suporte geológico local. 


\section{Referências}

BRASIL. Ministério das Minas e Energia. Secretaria-Geral. Projeto Radambrasil. Folha SE 21 Corumbá e parte da folha SE. 20; geologia, geomorfologia, pedologia, vegetação e uso potencial da terra. Rio de Janeiro, 1982.

BRASIL. Ministério do Meio Ambiente, dos Recursos Hídricos e da Amazônia Legal. Plano de Conservação da Bacia do Alto Paraguai (Projeto Pantanal) PCBAP. Diagnóstico dos meios físico e biótico: meio físico. Brasília: PNMA, 1997. v. 2, t. 1, p. 283-300.

CADAVID GARCÍA, E. A. O clima no Pantanal Mato-grossense. Corumbá: Embrapa-CPAP, 1984. (Embrapa-CPAP. Circular Técnica, 14).

CAMARGO, A. P. et al. Aptidão climática de culturas agrícolas. In: São Paulo, Secretaria da Agricultura. Zoneamento Agrícola do Estado de São Paulo. São Paulo, v. 1, 1974, p. 109-149.

CONTI, J. B. A natureza nos caminhos do turismo. In: RODRIGUES, A. B. (Org.). Turismo e ambiente: reflexões e propostas. 2. ed. São Paulo: Hucitec, 1997.

D’ ANGIOLELlA, G.; VASCONCELlOS, V. L. D.; ROSA, J. W. C. Estimativa e espacialização do balanço hídrico na Mesorregião Sul da Bahia. Anais do XII Simpósio Brasileiro de Sensoriamento Remoto, Goiânia, Brasil, INPE, v. 16, n. 21, p. 83-90, 2005.

DERPSCH, R.; SIDIRAS, N.; HEINZMAN, F. X. Manejo do solo com coberturas verdes de inverno. Pesquisa Agropecuária Brasileira, Brasília, v. 20, n. 7, p. 761773, 1985.

EMBRAPA. Levantamento e mapeamento dos remanescentes da cobertura vegetal do bioma Pantanal, período de 2002, na escala de 1:250.000 (Probio-Pantanal). Embrapa Informática Agropecuária: Campinas/SP, ago. 2004.

LAMBERTS, R. et. al. Desempenho térmico de edificações. Florianópolis, 1995. 82p. Disponível em: http://www.labeee.ufsc.br/graduacao/ecv_5161/ApostilaECV5161_ Versao2005_Modulo1.pdf. Acesso em: 6 ago. 2010.

MARTÍN, B. G. La relación clima-turismo: consideraciones básicas em los fundamentos teóricos y prácticos. Investigaciones geográficas, n. 21, 1999. p. 21-34. Edición digital: Alicante: Biblioteca Virtual Miguel de Cervantes 2000. Disponível em: http://www.cervantesvirtual.com. Acesso em: 6 ago. 2010.

PEREIRA, A. R.; ANGELOCCI, L. R.; SENTELHAS, P. C. Agrometeorologia: fundamentos e aplicações práticas. Ed. Agropecuária, 2002.

RESENDE, M; SANDANIELO, A; COUTO, E.G. Zoneamento agroecológico do sudoeste do Estado de Mato Grosso. Cuiabá/MT; EMPAER/MT, 1994.

ROSSATO, L. ALVALÁ, R. C. S.; TOMASELLA, J. Variação espaço-temporal da umidade do solo no Brasil: análise das condições médias para o período de 19711990. Revista Brasileira de Meteorologia, v. 19, n. 2, p. 113-122, 2004.

SENTELHAS, P. R.; PEREIRA, A. R.; ANGELOCCI, L. R. Meteorologia agrícola. Piracicaba: ESALQ, 1998. 
SORIANO, M. A. Climatologia. In: Zoneamento ambiental da Borda Oeste do Pantanal: maciço do Urucum e adjacências. In: SILVA, J. S. V. (Org.). Brasília-DF: Embrapa Comunicação para Transferência de Tecnologia, p. 69-81, 2000.

THORNTHWAITE, C. W.; MATHER, J. R. The water balance. Publications in Climatology. New Jersey: Drexel Institute of Technology, 1955.

THORNTHWAITE, C. W. An approach toward a rational classification of climate. Geogr. Rev., v. 38, p. 55-94, 1948.

VIANELlO, R. L.; Alves, A. R. Meteorologia básica e aplicações. Viçosa: UFV, 1991.

Sandra Mara Alves da Silva Neves - Mestre em Geografia pela Universidade Estadual Paulista. Doutorado em Geografia pela Universidade Federal do Rio de Janeiro. Professora e Pesquisadora do Grupo de Pesquisa em Sensoriamento Remoto, Ensino e Pesquisa em Geografia (SERPEGEO) - UNEMAT.

Maria Cândida Moitinho Nunes - Engenheira Agrícola. Mestre em Ciências (Agronomia - Física do Solo) pela Universidade Federal de Pelotas. Doutorado em Agronomia (Ciência do Solo) pela Universidade Federal do Rio Grande do Sul. Professora do Departamento de Agronomia da UNEMAT/Cáceres.

Ronaldo José Neves - Mestre em Geografia pela Universidade Estadual de Maringá. Doutorado em Geografia pela Universidade Federal do Rio de Janeiro. Professor e Pesquisador do Grupo de Pesquisa em Sensoriamento Remoto, Ensino e Pesquisa em Geografia (SERPEGEO) - UNEMAT. 